\title{
A cost-utility analysis of open and endoscopic carpal tunnel release
}

\author{
Achilleas Thoma MD MSc FRCSC FACS ${ }^{1,2,3}$, Vanessa H Wong MD ${ }^{1}$, Sheila Sprague MSc ${ }^{1,2,3}$, Eric Duku MSc PStat ${ }^{4}$
}

\begin{abstract}
A Thoma, VH Wong, S Sprague, E Duku. A cost-utility analysis of open and endoscopic carpal tunnel release. Can J Plast Surg 2006;14(1):15-20.
\end{abstract}

BACKGROUND: Open carpal tunnel release (OCTR) is the standard procedure for the surgical treatment of carpal tunnel syndrome. With the advent of minimally invasive surgery, endoscopic carpal tunnel release (ECTR) was introduced.

OBJECTIVE: To use a decision analytical model to compare ECTR with OCTR in an economic evaluation.

METHODS: Direct medical costs were obtained from a Canadian university hospital. Utility values obtained from experts, presented with carpal tunnel syndrome outcome health states, were transformed into quality-adjusted life years (QALYs). The probabilities of the health states associated with both techniques were obtained from the literature.

RESULTS: The incremental cost-utility ratio (ICUR) was $\$ 124,311.32 / \mathrm{QALY}$ gained, providing strong evidence to reject ECTR when ECTR is performed in the main operating room and OCTR is performed in the day surgery unit. A one-way sensitivity analysis in the present study demonstrated that when both OCTR and ECTR are performed in day surgery unit, the ICUR falls in the 'win-win' quadrant, making ECTR both more effective and less costly than OCTR. If the scar tenderness probability is decreased in the ECTR group in a second one-way sensitivity analysis, the ICUR decreases to $\$ 100,621.91 /$ QALY gained, providing evidence to reject ECTR. If the reflex sympathetic dystrophy probability is increased in the ECTR group in a third one-way sensitivity analysis, the ICUR increases to $\$ 202,657.88 /$ QALY gained, providing strong evidence to reject ECTR. CONCLUSIONS: There is still uncertainty associated with the costs and effectiveness of ECTR and OCTR. To obtain a definitive answer as to whether the ECTR is more effective than the OCTR, it is necessary to perform a large, randomized, controlled trial in which the utilities and resource use are measured prospectively.

Key Words: Cost utility; Economic analysis; Endoscopic carpal tunnel release; Open carpal tunnel release

\author{
Une analyse coût-utilité de la libération \\ ouverte ou endoscopique du canal carpien
}

HISTORIQUE : La libération ouverte du canal carpien (LOCC) est le traitement chirurgical standard du syndrome du canal carpien. Avec l'arrivée des opérations à effraction minimales, la libération endoscopique du canal carpien (LECC) s'est ajoutée.

OBJECTIF : Utiliser un modèle d'analyse décisionnelle pour comparer la LECC à la LOCC dans le cadre d'une évaluation économique.

MÉTHODOLOGIE : Les frais médicaux directs ont été obtenus auprès d'un hôpital universitaire canadien. Les valeurs utilitaires transmises par des spécialistes, accompagnées des issues d'états de santé du syndrome du canal carpien, ont été transformées en années de vie pondérées par la qualité (AVPQ). Les probabilités d'états de santé associés aux deux techniques ont été tirées de publications médicales.

RÉSULTATS : Le ratio coût-utilité incrémentiel (RCUI) correspondait à 124 311,32 \$ de gain d'AVPQ, ce qui fournit de solides données probantes pour rejeter la LECC lorsque celle-ci est effectuée dans la salle d'opération principale et que la LOCC l'est à l'unité de chirurgie d'un jour. Dans le cadre de la présente étude, une analyse de sensibilité unidirectionnelle a démontré que lorsque tant la LOCC que la LECC sont exécutées à l'unité de chirurgie d'un jour, le RCUI passe dans le quadrant « gagnant-gagnant », ce qui rend la LECC à la fois plus efficace et moins coûteuse que la LOCC. Si la probabilité de sensibilité des cicatrices diminue au sein du groupe ayant subi la LECC dans le cadre d'une deuxième analyse de sensibilité unidirectionnelle, le RCUI chute à 100 621,91 \$ de gain d'AVPQ, ce qui procure des données pour rejeter la LECC. Si la probabilité de dystrophie sympathique réflexe augmente au sein du groupe ayant subi une LECC selon une troisième analyse de sensibilité unidirectionnelle, le RCUI passe à 202 657,88 \$ de gain d'AVPQ, ce qui fournit des données probantes pour rejeter la LECC.

CONCLUSIONS : Il reste des incertitudes quant au coût et à l'efficacité de la LECC et de la LOCC. Afin d'établir à coup sûr si la LECC est plus efficace que la LOCC, il faut procéder à une étude aléatoire et contrôlée à large échelle au cours de laquelle l'utilité et les ressources seront mesurées de manière prospective.

\footnotetext{
Carpal tunnel syndrome (CTS), which affects $1 \%$ of the $C_{\text {population, is generally regarded as the most common of }}$ the nerve compression syndromes of the upper extremity $(1,2)$. In some occupations, where there is repetitive hand and wrist motion, the prevalence of CTS is much higher (3). The initial recommended treatment of CTS consists of work adjustment, anti-inflammatory drugs, wrist splints and steroid injection in
}

the carpal tunnel $(4,5)$. It is generally accepted that the definitive treatment of this condition is the surgical release of the transverse carpal ligament which overlies the compressed median nerve.

The success of this procedure is high, with a patient satisfaction of $84 \%$ (6). One of the main drawbacks of the procedure is scar tenderness (7). The introduction of the endoscopic

${ }^{1}$ Department of Surgery, Division of Plastic and Reconstructive Surgery, St Joseph's Healthcare, Hamilton; ${ }^{2}$ Surgical Outcomes Research Centre

(SOURCE), McMaster University, Hamilton; ${ }^{3}$ Department of Clinical Epidemiology and Biostatistics, McMaster University, Hamilton;

${ }^{4}$ Department of Psychiatry and Behavioural Neurosciences, McMaster University, Hamilton, Ontario

Correspondence: Dr Achilleas Thoma, 206 James Street South, Suite 101, Hamilton, Ontario L8P 3A9. Telephone 905-523-0019,

fax 905-523-0225, e-mail athoma@mcmaster.ca 


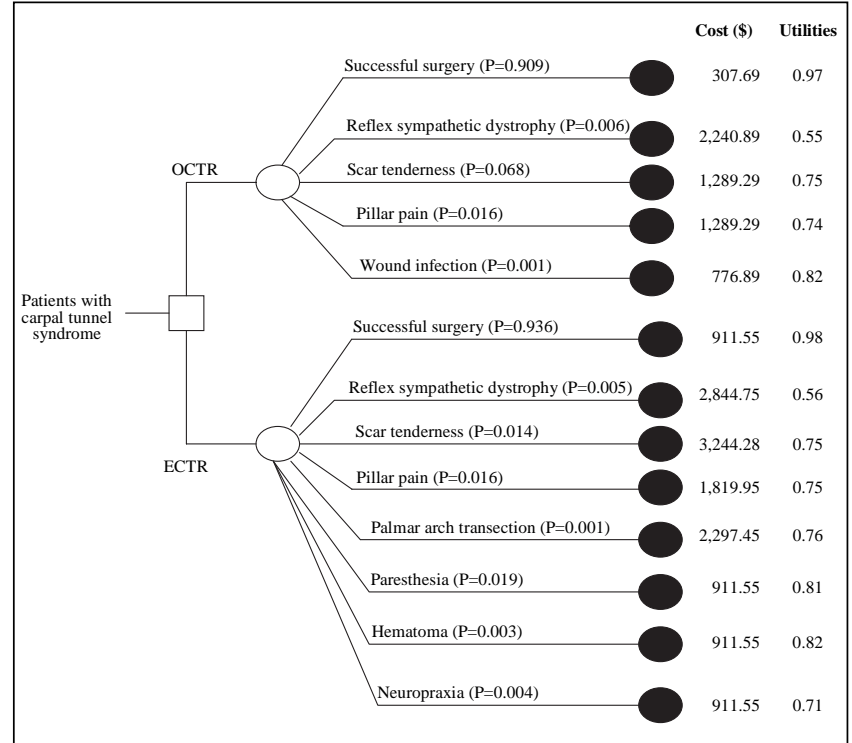

Figure 1) Decision tree for open (OCTR) and endoscopic carpal tunnel release (ECTR). Health state pathways and probabilities used to calculate cost and utility for each pathway associated with OCTR and ECTR

carpal tunnel release (ECTR) seemed to have reduced the incidence of scar tenderness (6). With regard to return to work, there remains some controversy. Some studies have found that ECTR patients return to work earlier $(6,8-15)$ and some other studies have determined that there is no difference in time off work (16-21). Part of the controversy may be how return to work was measured in the different studies (22).

A recent meta-analysis (23) found that ECTR is favoured over the open carpal tunnel release (OCTR) in terms of a reduction in scar tenderness and increase in grip and pinch strength at a 12 -week follow-up. With regard to symptom relief and return to work, these authors (23) concluded that the data are inconclusive. There is an increased susceptibility to reversible nerve injury that is three times more likely to occur with ECTR as with OCTR (23).

Although there is general agreement that the scar from the ECTR technique is less painful, the potential transection of the median nerve with its ramifications makes ECTR a controversial technique (24). The inadvertent transection of the median nerve featured prominently in previous cost-effectiveness analysis (25) and decision analysis (24) articles. Recent clinical research (23), however, identified that irreversible nerve damage is rare and can occur in either the OCTR or the ECTR technique. This serious complication has not been reported in previous, randomized, controlled trials. As a result, the only cost-effectiveness analysis reported by Chung et al (25) needs reconsideration.

The endoscopic technique has been tacitly accepted as an alternative technique to OCTR even though it is more costly and has not been adequately evaluated with appropriate health economic techniques. There is a strong need to re-examine the cost-effectiveness of ECTR versus OCTR with a new economic analysis based on the new evidence provided by a recent metaanalysis (23). The objective of the present study was to perform an economic evaluation comparing OCTR with endoscopic release in a Canadian university teaching hospital. The question the present study intended to address was whether ECTR is more cost-effective than the open method in the Canadian health care system.

\section{METHODS}

Perspective of the economic analysis

A number of perspectives can be taken in an economic evaluation including the patient, hospital, primary payer or society. When considering costs and consequences, it is important that one is explicit on the perspective taken. In addition to the direct health care costs, a surgical procedure also includes costs related to 'time off work' and reduced productivity. If these costs are not included, the analysis will certainly overlook an important financial burden to the patient, his or her family and society in general. A societal perspective would include both direct as well as productivity costs. For the present study, the primary payer's perspective was adopted, which in the province of Ontario is the Ministry of Health and Long-Term Care. This perspective is the most reasonable because the costs can be estimated more accurately. A societal perspective would be inaccurate in the absence of an economic analysis carried side by side to a randomized controlled trial that compared the two techniques.

\section{Health states}

For this analysis, the probabilities of the health states associated with ECTR and OCTR were obtained from the literature. These health states were based on complications or outcomes associated with endoscopic and open release of the carpal ligament identified in a recent meta-analysis (23) combining the data from 13 randomized controlled trials comparing ECTR with OCTR. The health states included for each procedure are shown in Figure 1. The complication of nerve transection was excluded from the analysis because it has not been reported in the previous randomized trials and it would be inappropriate to include in the analysis.

\section{Utilities and effectiveness}

The effectiveness of a surgical procedure can be measured in terms of lives saved, limbs saved or days off work averted. Such measurement outcomes, however, do not allow one to compare the benefits across different types of medical interventions, for example, coronary bypass versus limb transplantation. Utility as the measure of effectiveness was used. Cost-utility analysis is able to incorporate the increase in the quality of life or reduced morbidity. Third-party payers, such as the Ministry of Health and Long-Term Care, would prefer this type of presentation of effectiveness because they need to decide where to allocate scarce health care resources.

There are different approaches to utility measurement. Utilities (preferences) are global health-related quality of life measures. They can be obtained from a visual analogue scale, such as the 'feeling thermometer', standard gamble or time-tradeoff, or from generic scales, such as the Health Utilities Index (26-28).

For the present study, because no sampled utility data were available, only a deterministic analysis could be undertaken. Utilities (preferences) were obtained by presenting various scenarios associated with CTS outcomes to a sample of convenience of 19 Canadian experts (17 plastic surgeons and two plastic surgery residents with interest in hand surgery) who are knowledgeable about these health states. The scenario of each health state was presented to each expert who was asked to rank his or her preference such that the quality of life for each scenario was marked from a score of 0 (representing death) to 10 (representing perfect health) (29). For temporary states, such as infection, a time frame 


\begin{tabular}{|c|c|c|c|c|}
\hline \multirow{5}{*}{$\begin{array}{l}\text { Incremental } \\
\text { cost }\end{array}$} & \multicolumn{4}{|c|}{ Incremental effectiveness } \\
\hline & & More & Same & Less \\
\hline & More & 7 & 4 & 2 \\
\hline & Same & 3 & 9 & 5 \\
\hline & Less & 1 & 6 & 8 \\
\hline
\end{tabular}

Figure 2) Incremental effectiveness of new surgical intervention compared with surgical control. Nine possible outcomes in the comparison of cost with effectiveness of two surgical interventions. Adapted from reference 32

was specified in each scenario. For chronic states, such as permanent numbness of the hand for the remainder of the patient's life and median nerve laceration, it was assumed that the experts would discount the utilities for future years. Finally, the mean utility values for each health state were converted to quality-adjusted life years (QALYs).

\section{Costs}

The validity of a cost-effectiveness analysis depends to a great extent on the accurate estimation of the costs (29). Direct medical costs included the actual costs in resource use attributable to the surgical interventions. The total cost identified in the present study was the sum of physician fees (surgeon and anesthetist), hospital costs and physiotherapy costs. The expected costs were calculated by multiplying the total cost of a health state by the probability of the pathway of the health state occurring. If a major complication occurred and the patient required additional surgery, this would take place in the main operating room. The costs in such a case were calculated appropriately from data obtained from the Budgeting Department at St Joseph's Hospital, Hamilton, Ontario (a McMaster University teaching hospital).

At St Joseph's Hospital, ECTR requires use of the main operating room for $1 \mathrm{~h}$ and general anesthesia, in contrast with the open method, which is performed in half an hour under local anesthesia in the day surgery unit, a less formal operating room environment, which is staffed by only one nurse.

The anesthesia costs were calculated per Ontario Ministry of Health and Long-Term Care Schedule of Benefits (OMHSB) (30). It was assumed that the two main complications (infection and palmar arch laceration) would require an additional hour of surgery. It was also assumed that all procedures would be performed between 07:00 and 17:00 because the surgical fees increase between 17:00 and 07:00.

The physiotherapy costs included the initial consultation fee, and subsequent visits were obtained from the OMHSB for Physiotherapy, 2003 (31). The total costs were estimated by multiplying the number of visits to physiotherapy by the cost of each visit. For the purpose of the present study we only considered Ontario Health Insurance Plan fees.

Certain assumptions were made regarding physiotherapy. Physiotherapy was necessary for three months if infection ensued after surgery, and the average patient would require three physiotherapy visits per week.

When one surgical intervention is compared with another, there are nine possible outcomes (Figure 2) (32). If a new intervention

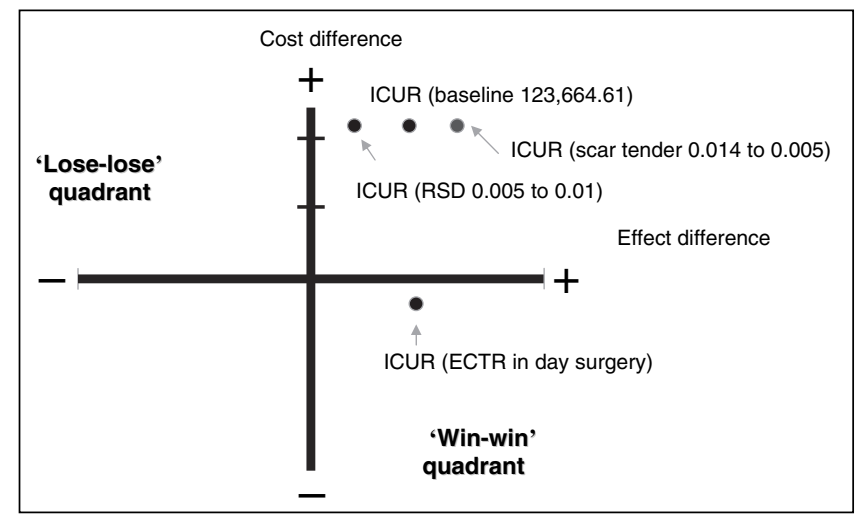

Figure 3) Cost-effectiveness plane showing the study results and the sensitivity analyses. ECTR Endoscopic carpal tunnel release; ICUR Incremental cost-utility ratio; RSD Reflex sympathetic dystrophy

falls into square 1 (lower left quadrant), it is said to be dominant and provides strong evidence for adoption because it is less expensive and more effective. If it falls into square 2 (upper right quadrant) there is strong dominance to reject the intervention because it costs more and is less effective. Of most interest is square 7 (upper left quadrant), the category in which most novel surgical interventions generally fall. That is, although the cost is higher, the intervention is more effective.

\section{Calculation of the incremental cost-utility ratio}

The correct way of comparing two surgical interventions is to determine the added benefit that is gained from the added unit cost. This 'incremental cost-utility ratio (ICUR)' is calculated as follows:

$$
\begin{gathered}
\text { ICUR }=\Delta \text { cost } / \Delta \text { utility } \\
=\left({\text { mean } \operatorname{cost}_{\text {ECTR }}-\text { mean cost }}_{\text {OCTR }}\right) / \\
\left(\text { mean } \text { QALY }_{\text {ECTR }}-\right.\text { mean QALY } \\
\text { OCTR }
\end{gathered}
$$

where the numerator represents the marginal difference of the mean cost of each intervention and the denominator represents the marginal mean difference of the effectiveness $(29,32)$. The expected costs were calculated by multiplying the total cost of a 'health state' by the probability of that 'health state' occurring. The total expected cost was the sum of the expected cost of the successful surgery plus the sum of the expected cost of all complications. For example, the expected costs for reflex sympathetic dystrophy would be calculated as follows: the estimated cost $(\$ 2,196.00)$ is multiplied by the probability of the complication occurring (in this case, 0.005821 ) to give an expected cost of $\$ 12.78$.

Figure 3 shows a cost-effectiveness plane where there are four quadrants representing different conclusions for the surgical release techniques described. If a technique provides a gain in QALYs at a lower cost, the ICUR falls into the 'win-win' (bottom right) quadrant of the cost-effectiveness plane, providing evidence to adopt this technique. If a technique provides fewer QALYs at a higher cost, the ICUR falls into the 'lose-lose' quadrant (upper left), favouring rejection of the technique. If the technique provides more QALYs at a higher cost, it falls in the upper right quadrant. If the technique is less costly with fewer QALYs, the ICUR falls within the bottom left quadrant. If the results fall into the latter two quadrants (upper right and bottom left), the magnitude of 


\section{TABLE 1}

Expected costs and expected quality-adjusted life years (QALYs)

\begin{tabular}{lrrrrr}
\hline CTS outcome health & \multicolumn{2}{c}{ Expected cost $(\$)$} & & Expected QALYs \\
\cline { 2 - 3 } \cline { 5 - 6 } state & OCTR & ECTR & & OCTR & ECTR \\
\hline Goes well & 238.94 & 895.61 & 36.37 & 37.46 \\
Reflex sympathetic dystrophy & 12.78 & 15.64 & 0.23 & 0.21 \\
Pillar pain & 20.28 & 32.81 & 0.65 & 0.70 \\
Scar tenderness & 84.02 & 43.90 & 2.69 & 0.54 \\
Wound infection & 0.85 & N/A & 0.04 & N/A \\
Palmar arch transection & N/A & 3.17 & N/A & 0.05 \\
Paresthesia & N/A & 18.12 & N/A & 0.76 \\
Hematoma & N/A & 2.59 & N/A & 0.11 \\
Neuropraxia & N/A & 3.88 & N/A & 0.16 \\
ICUR & 356.87 & $1,015.72$ & 39.987 & 39.992
\end{tabular}

CTS Carpal tunnel syndrome; ECTR Endoscopic carpal tunnel release; ICUR Incremental cost-utility ratio; OCTR Open carpal tunnel release; N/A Not applicable

the ICUR becomes an important deciding factor whether to accept or reject the technique.

\section{Sensitivity analyses}

Due to the uncertainty in the estimated costs and effectiveness, one-way sensitivity analyses were performed by altering the probabilities of the various complications and recalculating the ICUR. A one-way sensitivity was performed by altering the location where the surgery was performed (day surgery unit instead of the operating room) and by altering the probabilities of the health states, including the scar tenderness and the reflex sympathetic dystrophy.

\section{RESULTS}

\section{Health states}

The probabilities for the health states for this analysis were obtained from 16 randomized, controlled trials comparing ECTR with OCTR $(6,8-21,33)$. When these 16 randomized controlled trials were combined, the total number of ECTRs performed was 739 and the total number OCTRs performed was $859(6,8-21,33)$. The probabilities of each outcome state are shown in Figure 1. The pathways and probabilities comparing the two techniques were modified from a decision analytical model (24). The main modifications were the exclusion of the median nerve transection and the addition of scar tenderness as an important health state.

\section{Utilities and effectiveness}

The mean utilities (preferences) obtained by presenting various scenarios associated with CTS outcomes to 19 Canadian experts for each scenario are presented in Table 1. The mean utility scores for each health state were converted to QALYs and the total QALYs gained for ECTR was 39.992 and the total QALYs gained for OCTR was 39.987. (The raw data are available by request.)

\section{Costs}

In 2003, the physician payment for carpal tunnel release in Ontario was $\$ 153.45$ (Code N290 OMHSB September 1, 2003) (30). This fee was the same for either the open or the comparator technique (endoscopic) used in the present study. That is, the surgeon is not reimbursed for the additional effort of endoscopic release. In Canada, the hospital cost was calculated on a per diem basis. The variable direct cost of one procedure in the day surgery unit (St Joseph's Hospital) with an average time of $30 \mathrm{~min}$ is $\$ 109.35$. (Breakdown: salaries per case $=\$ 95.49$, drugs and medicines $=\$ 4.12$, medical supplies per case $=\$ 7.36$, supplies per case $=\$ 0.99$ and depreciation $=$ $\$ 1.39$.) The cost of a registered step eight nurse is $\$ 33.75 / \mathrm{h} \times 1.33=\$ 44.8875=\$ 44.89$.

It was assumed that if a major complication occurred and the patient required additional surgery, this would take place in the main operating room. The costs in such a case were calculated appropriately from data obtained from the Budgeting Department at St Joseph's Hospital. The variable cost in using the main operating room was $\$ 713.94 / \mathrm{h}$ and the fully loaded cost (including $35.0 \%$ overhead) was $\$ 963.82 /$ hour. The variable cost was used in the analyses.

It was also assumed that serious complications that would require additional surgery would take place in the main operating room. For example, infection, the cost of which was estimated as the cost to drain a flexor sheath, was estimated to be $\$ 144.70$ and the cost of surgical vascular repair was estimated to be $\$ 517.40$. Each of these complications was assumed to take $1 \mathrm{~h}$ to manage except the infection drainage which would require only half an hour. The surgical fees were derived from the OMHSB (30).

The anesthesic fees were based on the formula $\$ 11.04$ per unit. Each $1 \mathrm{~h}$ procedure was worth four units. Additionally each procedure has a number of basic units, which are used in the calculation. Assuming that each of the main complications would require an additional hour of surgery, the anesthetic fees would have been as follows: for drainage of infection $\$ 11.04 \times$ six units (four basic + two time units) and for vascular repair $\$ 11.04$ $\times 14$ units ( 10 basic + four time units). It was also assumed that all procedures would be performed between 07:00 and 17:00 because the surgical fees increase between 17:00 and 07:00.

The physiotherapy costs included the initial consultation fee of $\$ 30.00$ and subsequent visits valued at $\$ 12.20$ per visit (31). The total costs were estimated by multiplying the number of visits to physiotherapy by the cost of each visit. For the purpose of the present study, only Ontario Health Insurance Plan fees were considered.

The combined costs associated with each health state are summarized in Figure 1. The mean cost of ECTR was $\$ 1015.72$ and the mean cost of OCTR was $\$ 356.87$ (Table 1).

\section{Calculation of the ICUR}

If the endoscopic technique was performed in the main operating room and the open technique was performed in the day surgery unit, the baseline ICUR obtained was (Table 2):

$$
\begin{gathered}
\text { ICUR }=\Delta \text { cost } / \Delta Q A L Y \\
=(\$ 1,015.72-\$ 356.87) /(39.9922-39.9869) \\
=\$ 658.85 / 0.0053 \\
=\$ 124,311.32 / \text { QALY gained }
\end{gathered}
$$

An ICUR of $\$ 124,311.32 / \mathrm{QALY}$ gained falls into the upper right quadrant of the cost-effectiveness plane (Figure 3).

\section{Sensitivity analyses}

The results of the one-way sensitivity analysis are shown in Table 2. If both OCTR and ECTR were performed in the day surgery unit the ICUR fell into the 'win-win' quadrant of the 
cost-effectiveness, making ECTR cost-effective. This would favour the adoption of the endoscopic technique (Figure 3). If the scar tenderness probability were changed in the ECTR group from 0.014 to 0.005 , the ICUR would decrease to $\$ 100,621.91 /$ QALY gained. If the reflex sympathetic dystrophy probability were increased from 0.005 to 0.01 for the ECTR, the ICUR would increase to $\$ 202,657.88 /$ QALY gained (Figure 3).

\section{DISCUSSION}

The decision analytical model is an appropriate approach in the performance of a cost-effectiveness analysis in surgical interventions where sampled data are not available. The drawback, however, of such a deterministic analysis, as in the present case comparing the endoscopic with the open method, is the uncertainty associated with the costs and the probabilities of the different complications and pathways. In such a model, one additionally infers that the utilities obtained by experts represent the utilities of the patients. Although there is some controversy as to who should provide the utilities $(28,29,34)$, there is general agreement that patients or members of the general population are better candidates to provide utilities than experts $(29,34)$. In our study, experts were used to provide utilities for practical reasons because they are familiar with health states associated with various complications (28).

In this economic analysis we did not include the capital costs associated with the equipment required for the ECTR technique. Because the cost of the day surgery unit is calculated per diem and the cost of purchasing the ECTR equipment is a one-time charge, the cost of the additional blade used in each ECTR case is not captured in this analysis.

There was variation in the probabilities in the different complications in the 16 included studies (6,8-21,33). Unfortunately, the more serious complications (such as inadvertent transections of the median nerve) that occur in carpal tunnel surgery are usually unreported in the surgical literature. If these true complication probabilities are not included in the decision analytical tree, incorrect conclusions can be reached.

While ECTR cost is approximately 2.4 times more than that of the OCTR release, there was only a small increase in QALYs provided by ECTR. The ICUR was $\$ 124,311.32$ / QALY. According to the quantitative thresholds for cost per QALY gained by Laupacis et al (35), this ICUR provides strong evidence to reject the adoption of ECTR. Laupacis et al (35) suggest that if a new program is more effective and more costly than the existing one but costs less than $\$ 20,000$ per QALY gained, there exists strong evidence for adoption of the new technique. Similarly, $\$ 20,000$ to $\$ 100,000$ per QALY gained provides moderate evidence for adoption, and more than $\$ 100,000$ per QALY gained provides weak evidence for adoption and strong evidence for rejection.

A one-way sensitivity analysis in the present study has demonstrated that when both OCTR and ECTR are performed in the day surgery unit the ICUR falls into the 'winwin' quadrant on the cost-effectiveness plane, making ECTR both more effective and less costly than OCTR. This provides strong evidence for the adoption of the endoscopic technique. In our centre, the configuration of the day surgery unit did not allow us to perform the endoscopic technique in this location. The reader needs to decide for him- or herself whether to adopt this technique based on individual circumstances. If the scar tenderness probability is changed in the ECTR group from
TABLE 2

Baseline and sensitivity analysis

\begin{tabular}{lccc}
\hline Analysis & $\begin{array}{c}\text { Cost difference } \\
\text { (\$) }\end{array}$ & $\begin{array}{c}\text { QALYs } \\
\text { gained }\end{array}$ & $\begin{array}{c}\text { ICUR } \\
\text { (\$/QALY) }\end{array}$ \\
\hline Baseline analysis & 658.84 & 0.0053 & $124,311.32$ \\
$\begin{array}{c}\text { Sensitivity analysis: ECTR } \\
\text { performed in day surgery unit }\end{array}$ & -25.41 & 0.0053 & Win-win \\
$\begin{array}{l}\text { Sensitivity analysis: Reflex } \\
\text { sympathetic dystrophy increase }\end{array}$ & 667.71 & 0.00329 & $202,657.88$ \\
in ECTR from 0.005 to 0.01 & & & \\
$\begin{array}{l}\text { Sensitivity analysis: Overall } \\
\text { decrease scar tenderness in }\end{array}$ & 639.32 & 0.00635 & $100,621.91$ \\
ECTR from 0.0135 to 0.005 & & & \\
\hline
\end{tabular}

ECTR Endoscopic carpal tunnel release; ICUR Incremental cost-utility ratio; QALY Quality-adjusted life year

0.014 to 0.005 (a plausible rate) in a second one-way sensitivity analysis, the ICUR decreases to $\$ 100,621.91 /$ QALY gained. This also provides evidence to reject ECTR. Alternatively, if the reflex sympathetic dystrophy probability is increased from 0.005 to 0.01 (also a plausible event) in a third one-way sensitivity analysis for ECTR, the ICUR increases to $\$ 202,657.88 /$ QALY gained. This ICUR provides evidence to reject ECTR.

Surprisingly, although the literature suggests a relationship between the tender scar after OCTR and absence from work, Vasen et al (24) did not include it in their decision analytical model. It is well known that 'return to work' is inversely related to the painful scar at the base of the palm $(6,36,37)$. In our decision analytical model, this complication had a probability of $6.8 \%$ for OCTR and the probability of scar tenderness was $1.4 \%(6,8-21,33)$. By not including this common complication in previous studies, with the endoscopic technique, one can bias the costs and utilities in favour of the endoscopic release. Sensitivity analysis has shown that by reducing the scar tenderness from $1.4 \%$ to $0.5 \%$, the endoscopic technique had an ICUR of $\$ 100,621.91 / Q A L Y$ gained. Because it was the tender scar with the traditional release that led to the evolution of the endoscopic technique, a sensitivity analysis including this variable is of paramount importance in future carpal tunnel economic evaluation studies. It is also imperative that future research be directed toward the measurement of the true incidence and utilities of the tender scar in both techniques.

We have used cost-utility analysis over cost-effectiveness analysis because it permits one to make a direct comparison between a number of different surgical interventions because consequences are reported in the same units (QALYs). Thirdparty payers such as the Ministry of Health and Long-Term Care would favour this type of presentation of effectiveness because the Ministry must decide where to allocate scarce health care resources $(29,32)$.

The marginal utility identified in this deterministic analysis favours only very slightly the endoscopic technique. As a result, a change in relative costs has a large impact on the ICUR. The above sensitivity analyses indicate that the ICUR is sensitive not only to the type of complication, but also its probability and the surgical environment in which a procedure is performed. The outcome used in the study was QALYs. Others have used 'days until return to work' for the costeffectiveness analysis (24,25). Vasen et al (24) reported that if the gain in 'return to work' with the endoscopic technique 
was only 10 days when compared with that of the open method, the open method would be less costly. Although, ideally, return to work reflects function and recovery, it is inadequately measured and reported in this literature (22). A recent review (22) revealed that in studies comparing OCTR with ECTR, there is lack of uniformity in reporting this outcome that may contribute to the inconclusive results for return to work, and future research needs to ensure that return to work is used in a consistent manner.

The uncertainty associated with the costs and utilities (effectiveness), however, leaves one uneasy about declaring that the endoscopic technique is superior to the open method

\section{REFERENCES}

1. Pfeffer GB, Gelberman RH, Boyes JH, Rydevik B. The history of carpal tunnel syndrome. J Hand Surg [Br] 1988;13:28-34.

2. Phalen GS. The carpal-tunnel syndrome. Clinical evaluation of 598 hands. Clin Orthop Relat Res 1972;83:29-40.

3. Zimmerman NB, Zimmerman SI, Clark GL. Neuropathy in the workplace. Hand Clin 1992;8:255-62.

4. Kasdan ML, Lane C, Merritt WH, Nathan PA. Carpal tunnel syndrome: Management techniques. Patient Care 1993;April:111-38.

5. Giannini F, Passero S, Cioni R, et al. Electrophysiologic evaluation of local steroid injection in carpal tunnel syndrome.

Arch Phys Med Rehabil 1991;72:738-42.

6. Brown RA, Gelberman RH, Seiler JG III, et al. Carpal tunnel release. A prospective, randomized assessment of open and endoscopic methods. J Bone Joint Surg Am 1993;75:1265-75.

7. Hulsizer DL, Staebler MP, Weiss AP, Akelman E. The results of revision carpal tunnel release following previous open versus endoscopic surgery. J Hand Surg [Am] 1998;23:865-9.

8. Agee JM, McCarroll HR Jr, Tortosa RD, Berry DA, Szabo RM, Peimer CA. Endoscopic release of the carpal tunnel: A randomized prospective multicenter study. J Hand Surg [Am] 1992;17:987-95.

9. Benedetti VR, Sennwald G. [Agee endoscopic decompression of the median nerve: Prospective study with comparison to open decompression.] Handchir Mikrochir Plast Chir 1996;28:151-5.

10. Erdmann MW. Endoscopic carpal tunnel decompression. J Hand Surg [Br] 1994;19:5-13.

11. Saw NL, Jones S, Shepstone L, Meyer M, Chapman PG, Logan AM. Early outcome and cost-effectiveness of endoscopic versus open carpal tunnel release: A randomized prospective trial. J Hand Surg [Br] 2003;28:444-9.

12. Schafer W, Sander KE, Walter A, Weitbrecht WU. [Agee endoscopic operation of carpal tunnel syndrome in comparison with open surgical technique.] Handchir Mikrochir Plast Chir 1996;28:143-6.

13. Sennwald GR, Benedetti R. The value of one-portal endoscopic carpal tunnel release: A prospective randomized study. Knee Surg Sports Traumatol Arthrosc 1995;3:113-6.

14. Stark B, Engkvist-Lofmark C. [Endoscopic operation or conventional open surgical technique in carpal tunnel syndrome: A prospective comparative study.] Handchir Mikrochir Plast Chir 1996;28:128-32.

15. Trumble TE, Diao E, Abrams RA, Gilbert-Anderson MM. Singleportal endoscopic carpal tunnel release compared with open release: A prospective, randomized trial. J Bone Joint Surg Am 2002;84A:1107-15.

16. Jacobsen $\mathrm{MB}$, Rahme $\mathrm{H}$. A prospective, randomized study with an independent observer comparing open carpal tunnel release with endoscopic carpal tunnel release. J Hand Surg [Br] 1996;21:202-4.

17. Dumontier C, Sokolow C, Leclercq C, Chauvin P. Early results of conventional versus two-portal endoscopic carpal tunnel release. A prospective study. J Hand Surg [Br] 1995;20:658-62.

18. Ferdinand RD, MacLean JG. Endoscopic versus open carpal tunnel release in bilateral carpal tunnel syndrome. A prospective, randomised, blinded assessment. J Bone Joint Surg Br 2002;84:375-9.

19. Foucher G, Buch N, Van Overstraeten L, Gautherie M, Jesel M. [Carpal tunnel syndrom. Can it still be a controversial topic?] Chirurgie 1993-94;119:80-4. even in the day surgery unit environment. To settle this issue it is necessary to perform a large, randomized, controlled trial consisting of several thousand patients as a multicentre initiative. Considering how common CTS is, this should not be an insurmountable problem. Both direct and opportunity costs can be 'piggybacked' to the randomized controlled trial, which would allow one to perform accurate cost-utility analyses.

FUNDING: No funding was received for the support of this manuscript. The present paper was presented at the Canadian Society of Plastic Surgeons Annual Meeting, June 9, 2005.

20. Hoefnagels WA, van Kleef JG, Mastenbroek GG, de Blok JA, Breukelman AJ, de Krom MC. [Surgical treatment of carpal tunnel syndrome: Endoscopic or classical (open)? A prospective randomized trial.] Ned Tijdschr Geneeskd 1997;141:878-82.

21. Macdermid JC, Richards RS, Roth JH, Ross DC, King GJ Endoscopic versus open carpal tunnel release: A randomized trial. J Hand Surg [Am] 2003;28:475-80.

22. Ayeni O, Thoma A, Haines T, Sprague S. Analysis of reporting return to work in studies comparing open with endoscopic carpal tunnel release: A review of randomized controlled trials. Can J Plast Surg 2005;13:181-7.

23. Thoma A, Veltri K, Haines T, Duku E. A meta-analysis of randomized controlled trials comparing endoscopic and open carpal tunnel decompression. Plast Reconstr Surg 2004;114:1137-46.

24. Vasen AP, Kuntz KM, Simmons BP, Katz JN. Open versus endoscopic carpal tunnel release: A decision analysis. J Hand Surg [Am] 1999;24:1109-17.

25. Chung KC, Walters MR, Greenfield ML, Chernew ME. Endoscopic versus open carpal tunnel release: A cost-effectiveness analysis. Plast Reconstr Surg 1998;102:1089-99.

26. Feeny DH, Torrance GW, Furlong WJ. Health utilities index. In: Spilker B, ed. Quality of Life Assessments in Clinical Trials, 2nd edn. New York: Raven Press, 1996:239-52.

27. Torrance GW. Measurement of health state utilities for economic appraisal. J Health Econom 1986;5:1-30.

28. Weeks J. Measurement of utilities and quality-adjusted survival. Oncology (Williston Park) 1995;9:67-70.

29. Drummond MF, O’Brien BJ, Stoddart GL, Torrance GW. Methods for the Economic Evaluation of Health Care Programmes, 2nd edn. Oxford: Oxford University Press, 1997.

30. Ministry of Health and Long-Term Care. Schedule of Benefits for Physician Services under the Health Insurance Act. Ottawa: Ministry of Health and Long-Term Care, 2003.

31. Ministry of Health and Long-Term Care. Schedule of Benefits for Physiotherapist Services under the Health Insurance Act. Ottawa: Ministry of Health and Long-Term Care, 2003.

32. Thoma A, Sprague S, Tandan V. Users' guide to the surgical literature: How to use an article on economic analysis. Can J Surg 2001;44:347-54.

33. Mackenzie DJ, Hainer R, Wheatley MJ. Early recovery after endoscopic vs short-incision open carpal tunnel release. Ann Plast Surg 2000;44:601-4.

34. Gold MR, Stiegel JE, Russell CB, Weinstein MC. CostEffectiveness in Health and Medicine. New York: Oxford University Press, 1996.

35. Laupacis A, Feeny D, Detsky AS, Tugwell PX. How attractive does a technology have to be to warrant adoption and utilization? Tentative guidelines for using clinical and economic evaluations. CMAJ 1992;146:473-81.

36. Agee JM, Peimer CA, Pyrek JD, Walsh WE. Endoscopic carpal tunnel release: A prospective study of complications and surgical experience. J Hand Surg [Am] 1995;20:165-71.

37. Chow JC. Endoscopic release of the carpal ligament: A new technique for carpal tunnel syndrome. Arthroscopy 1989;5:19-24. 